\title{
Visual form beyond traditional media - On the expression and construction of watercolor art in digital painting
}

\author{
Shan $\mathrm{Li}^{1,2}$ \\ ${ }^{1}$ Lecturer, School of fine arts, Baoji University of Arts and Sciences \\ ${ }^{2}$ Doctoral student of fine arts of Macao University of science and technology
}

\begin{abstract}
In the context of the development of digital image era and digital media art, watercolor art, as a traditional form of painting, will inevitably experience a subversive change and transformation of painting methods and ideas.By analyzing the artistic expression and construction process of watercolor art in digital painting, this paper finds out the aesthetic value and significance of watercolor art in digital painting, discusses the relationship between traditional watercolor painting and digital painting and the new space of watercolor development in the future.
\end{abstract}

\section{Introduction}

In recent years, with the advent of the digital and image era, "digital painting" has become a new art form derived from the integration of modern computer technology and painting art after "computer art", "computer painting" and "digital art".The cartographic system of computer technology is an effective way to connect with painting. It subverts and surpasses the manual attribute and the material medium attribute of traditional easel painting. "It can directly or indirectly convert the artistic image of the material form of the real world into digital information for storage, and can be reproduced and displayed in the form of photoelectricity at any time" (1), so that the graphic image of art can be realized the multiple forms of expression from simulated painting to static picture, and then to dynamic picture, making painting art enter into a virtual visual expression space. Gengyun Zhang believes that "the digitization of art will constitute the mainstream development trend of art reform in the 21st century" ${ }^{(2)}$.Facing the impact of new visual media, watercolor painting, as a traditional easel painting, needs to transcend the limitations of traditional art media and excavate its own aesthetic value in a broader art space while playing its unique artistic charm.

\section{Media attributes and artistic features of digital painting}

In the history of the development of Chinese painting art, from painting on cave walls to painted on colored pottery, and then to painting on silk, tough silk and paper, the material media of painting has always evolved with the development of the times.Today, the rapid development of science and technology has promoted the transformation of painting art.Digital painting, as a new form of visual art, has completely subverted the media properties of traditional painting, such as materiality and handcraft. Its main purpose is to "simulate the visual form characteristics of traditional painting language system" (3), such as simulating ink painting, oil painting, printmaking, watercolor painting, etc., and its media tools mainly rely on computer software technology and manual operation software drawing tools.At present, there are many kinds of software related to computer processing graphics and images, which are mainly divided into pixel painting and vector painting. For example, PhotoShop and Painter are generally used for pixel painting, while Illustrator, CorelDraw, Flash and other software are used for vector painting. These softwares have the common functions of processing the shape, color, light and shadow, line, texture, material and so on. Digital painting mainly uses computer, tablet computer iPad, smart phone, pressure sensitive board and pressure sensitive pen as painting tools, and digital camera, fax machine, laser photocopier and other auxiliary equipment for painting.

In the media, visual form and functional significance and other aspects, digital painting show different media attributes and artistic characteristics from traditional painting, the most prominent feature is the virtual, that is, painting in the virtual digital space makes digital painting produce a variety of advantages and characteristics. First of all, digital painting has the infinity and freedom of modification.Compared with the limitations of traditional painting in the process of creation or modification, which will destroy or stain the painting paper and canvas, as well as difficult to retain or reproduce the ingenious painting effect, digital painting can use digital technology to carry out unlimited arbitrary modification, copy, paste, rotation, scaling and so on.Artists no longer need to be anxious or worry about the non repeatability of the creation process. Computer technology can record and 
repeat every stage and process of creation, thus expanding the psychological space of artists.As Wangqiao Rong said, "the skill of digital painting is to free artists from their skills and avoid the mechanical and endless training of skills in the past, so that their genius imagination can gallop freely and create more appreciative works." ${ }^{(4)}$ Artists only need to freely and boldly play their own imagination and creativity, carry out various exploration and attempts of painting, and realize the maximum possibility of artistic creation goal.Secondly, digital painting has stylized and precise settings.In traditional painting, for example, Chinese painting has formed a complete and stylized painting paradigm and techniques for a long time, which has high artistic value and charm. This painting paradigm and technique has been gradually formed through the baptism of long years and time. While digital painting only needs to simulate the stylization of painting through computer technology and then convert it into database, which can produce large-scale and batch paintings with the same theme and style. The computer system can accurately use the data technology to determine the color and shade of the picture, including brightness, contrast, saturation and color equality, so as to maintain the continuity and consistency of painting. Thirdly, digital painting has multi-dimensional visual expression forms of static and dynamic, plane and three-dimensional.

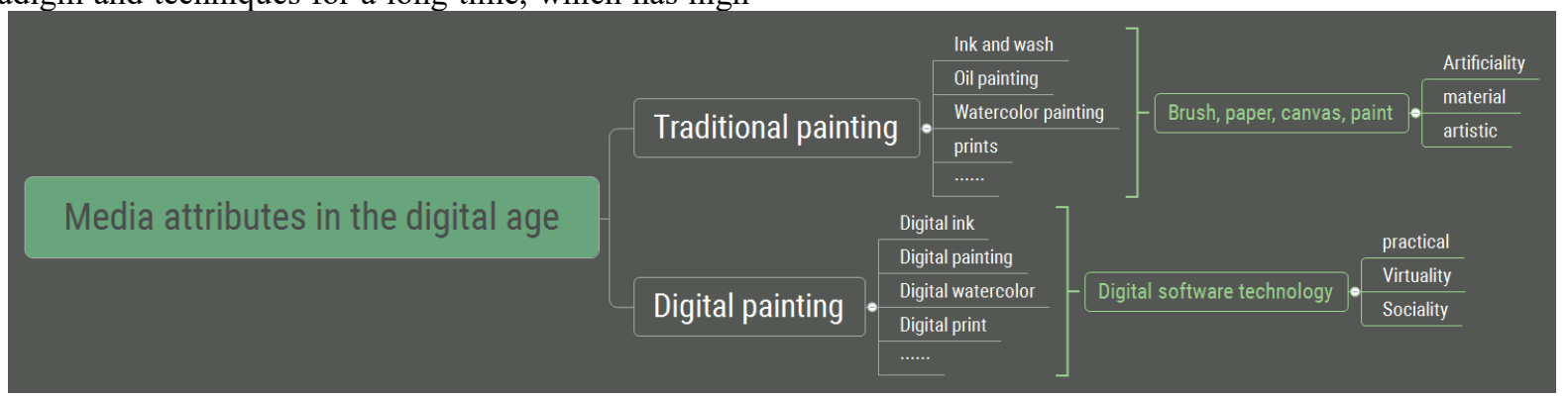

Media attributes in the digital age

Digital painting is not limited to the planarity and stillness of traditional painting. Computer technology can make animation model by using software according to the graphics and images of traditional painting to achieve dynamic and three-dimensional picture effect. At the same time, it can also change the shape, color, material and texture effect of the model to create a variety of visual art forms, thus expanding the performance space of visual art. Finally, in the information and market-oriented era, digital painting is widely used. Compared with the ornamental and materiality of traditional painting, digital painting has been used in painting, advertising, film and television, animation, online games, cartoon, graphic design, fashion design and other aspects, and developed into the public fields such as consulting industry, tourism industry, entertainment industry, media industry, etc., which makes traditional painting transform into practical, public and social attributes on the basis of artistic nature features.

\section{The artistic expression of watercolor art in digital painting}

Mr. Guanzhong $\mathrm{Wu}$ thinks that the beauty of watercolor painting lies in the combination of water and color.Traditional watercolor painting uses water mixed watercolor pigment to paint on paper, cloth and other material media. In addition, special blending agents such as cow bile, glue or oil are needed. The fluidity and transparency of water are used to infiltrate and blend with pigments on paper to produce unique texture effect and light and shade color changes, showing the artistic language and aesthetic characteristics of "the beauty of blending water and color" and "the beauty of vivid charm"(5).Digital watercolor presents a unique form of artistic expression through the combination of media materials, artistic language, visual style and aesthetic characteristics of traditional watercolor painting and computer technology.

\subsection{The simulation and reappearance of traditional watercolor art}

Aristotle believed that "human beings can acquire knowledge through imitation, and everyone can get pleasure from the results of imitation" (6).Traditional watercolor painting mainly relies on material media, such as watercolor pen, watercolor pigment, watercolor paper and so on.However, the internationally popular graphic and image software such as Painter and Procreate can simulate traditional watercolor painting tools and media materials, and use pressure sensitive pen, pressure sensitive board or operating handle to draw digital watercolor painting. These software simulates the types, sizes and thicknesses of watercolor pens, the thickenings and tints of watercolor paper lines, as well as the techniques and effects of various watercolor paintings, and even simulate and restore the touch experience between painters and tools, enabling the painter to create works just like manual painting.

On the one hand, in the creation process of traditional watercolor paintings, the painter needs to spend a lot of time to make creative sketches, and the non modifiable and unrepeatable nature of watercolor painting limit the painter's free imagination and play. With the help of graphic and image software, digital camera and scanner, the painter uses the creative means of digital painting to daub, modify and copy the picture at will, which makes the drawing process of creative sketch more convenient and fast, so as to realize his creative idea smoothly and provide a good premise and foundation for creation. On the other hand, some artists completely abandoned the media of traditional watercolor art, and used computer 
software to draw watercolor paintings, so as to achieve the purpose of artistic creation. They are widely used in painting, advertising, architecture, digital illustration, animation and other art fields.



David Hockney paints with iPad
In recent years, British contemporary painting master David Hockney used the most cutting-edge technology to participate in the creation of painting, and carried out a variety of subversive attempts and innovations. Among them, he used iPad to draw landscapes with watercolor effect. When painting on the iPad, the artist plans the size of the work to be printed by default, and uses completely different strokes and styles to paint according to the situation. These works were exhibited at the Royal Academy of Art in 2012. It can be seen that the simulation and reproduction of digital painting on watercolor art makes traditional watercolor painting obtain a broader performance space, and also enriches the visual style and artistic expression of digital painting.

\subsection{Re creation of traditional watercolor art}

In addition to simulating and reproducing the traditional static watercolor art effect, computer technology has realized the re creation of traditional watercolor art.Digital watercolor breaks through the limitation of traditional watercolor plane static image, and brings watercolor art into the visual space of three-dimensional, dynamic and sound.At present, 3DMax, Maya and Lightwave are the most popular 3D animation software in the world. On the one hand, 3D technology can create a virtual interactive space, which plays an important role in promoting the wide spread of watercolor painting.Traditional watercolor is usually displayed and displayed in a fixed physical space, while digital watercolor is constructed into a virtual display space through image, image and Internet technology. In this virtual space, the combination of dynamic, three-dimensional and sound display mode of watercolor painting can be realized. The viewer can not only interact with watercolor art anytime and anywhere, but also experience the multi-dimensional artistic feelings of vision, hearing and perception, creating an aesthetic field spanning time and space.It is particularly worth pointing out that due to the outbreak of the new crown epidemic this year, most art museum, galleries and auction companies were closed, and the artists' watercolor works could not be physically displayed as scheduled. Therefore, the relevant technical personnel used digital media technology to transform the entity watercolor painting into data, put it into a carefully created virtual exhibition space, and bring the audience in through Internet media technology.In the virtual three-dimensional exhibition hall, the audience can freely choose the viewing route and zoom in and out of the watercolor works, forming a good interactive relationship between the viewer and the works, achieving the same exhibition effect as the physical exhibition.

On the other hand, three-dimensional dynamic visual effects are widely used in modern film and television, network, advertising, animation and games. Digital painting can make the visual form of watercolor art into a three-dimensional dynamic picture through a series of technical means such as computer software construction model, material rendering, animation, etc., which can be used in various art fields, highlighting and enhancing the flow of watercolor art.The beauty of movement and color.At the G20 Summit held in Hangzhou, China in 2016, computer technology transformed the watercolor works painted by Gang Zhou into a three-dimensional dynamic picture of watercolor artistic effect, which was presented in the "Chinese Style · G20 · Publicity Video", which made the viewers intuitively feel the artistic charm of watercolor painting and appreciate the beauty of The West Lake in Hangzhou .In addition, computer technology also extracts and enlarges the media properties and artistic characteristics of watercolor art, such as fluidity, transparency, texture, granule, infiltration, etc., and makes it into a three-dimensional digital watercolor art, and combines it with other art forms, so as to create a new visual form and image, and provide multiple expression space for watercolor art. 




Digital watercolor material Autumn Forest

for the development of watercolor art.

\section{Aesthetic value and significance of watercolor art in digital painting}

The simulation and reconstruction of traditional watercolor art by computer technology has subverted the traditional material media, and digital painting has created new aesthetic characteristics and artistic value.

First of all, digital watercolor expands the visual beauty of traditional watercolor art and provides more development space for the development of traditional watercolor art.In recent years, traditional watercolor painting has made remarkable artistic achievements in media materials, language form and artistic connotation.However, the development of Internet technology and digital media art has had a huge impact on the development of traditional painting.In this context, watercolor painting has gradually lost its vitality and can no longer meet the public's visual pursuit of this evolution.Therefore, digital watercolor has got rid of the shackles of traditional media, changed the traditional thinking and concept of painting, brought watercolor art into a new visual space, and provided more possibilities

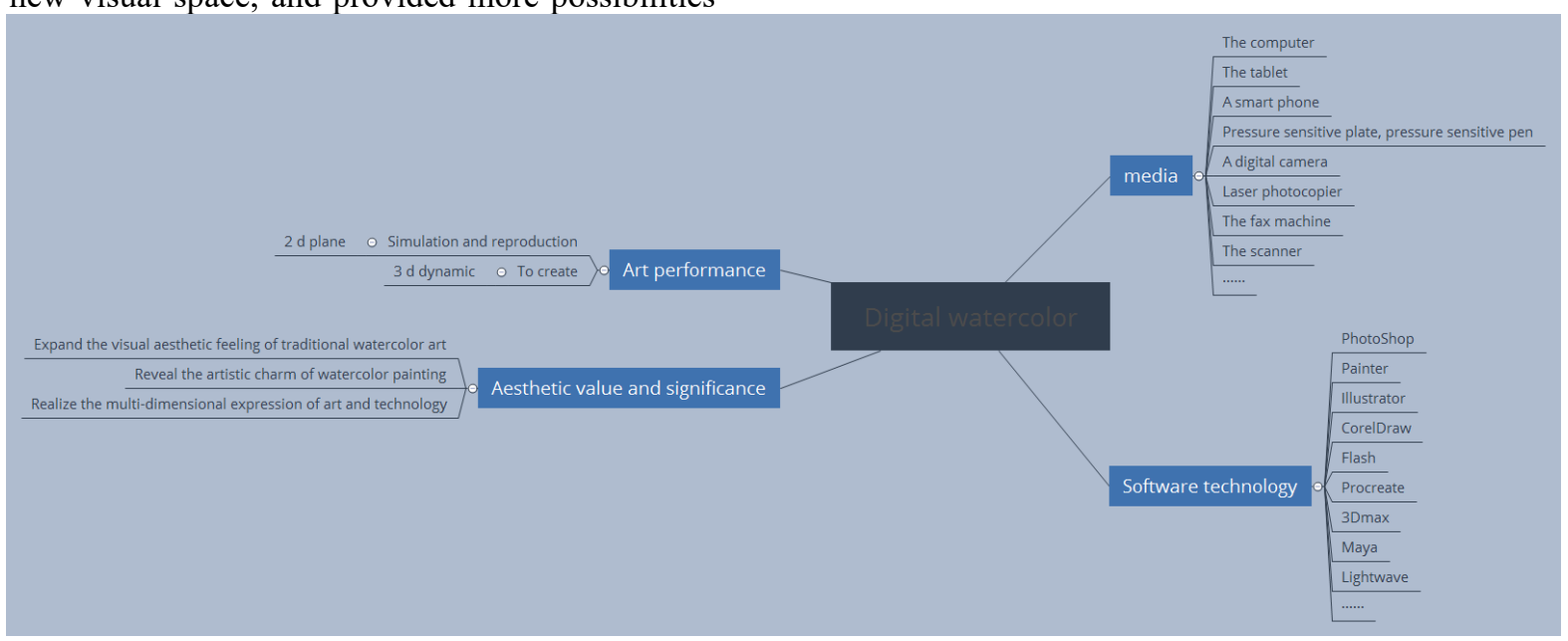

The construction of digital watercolor art

Finally, digital watercolor breaks through the limitations of traditional watercolor material media and
Secondly, the digital watercolor has crossed the fence of "small type of painting", showing the artistic charm of watercolor painting. The status of watercolor painting in traditional painting is not high. It has been called "small painting" and "light music", which has not been widely recognized by the public.However, digital painting widely absorbs the artistic elements of all kinds of paintings, breaking the types and boundaries of painting. Computer technology can present new visual forms through the simulation and reconstruction of any kind of painting. Thus, digital painting such as "digital watercolor", "digital oil painting", "digital print", "digital ink painting" and so on came into being.Watercolor art, like other paintings, is widely used in various fields of society. At the same time, watercolor art is an aesthetic model of integration of China and the West. It has both Western perspective space modeling and rich colors, and Chinese ink and wash's virtual reality and vivid charm. It is incomparable to other kinds of paintings. Therefore, it can fully display its artistic value and charm in digital painting. realizes multi-dimensional expression and experience of technology and art. Digital watercolor realizes paperless 
creation, and the painter does not need to consider the strict procedure and technicality of traditional watercolor painting techniques. He can create watercolor art with his own will, which provides a variety of possibilities for exploration. Computer technology makes watercolor art image from physical space to virtual space, from plane static to three-dimensional dynamic, so that the viewer can experience the painter's multi-dimensional fusion and expression of vision, hearing and touch to construct a free, open, cross space-time interactive space, so that the aesthetic realm of watercolor art has been highly sublimated.

\section{Conclusion}

"The material of painting, as the undertaker of painting works, is the first level that can not be overstepped by painting art language." (7) The simulation and reconstruction of traditional watercolor art by digital painting surpasses the visual experience of traditional painting media. Traditional watercolor art and digital watercolor art interact, influence and complement each other, providing multiple artistic expression space for artistic activities in various fields of society.However, the emergence of any new things like coins have two sides, digital painting reflects the computer graphics and image technology language, not artistic creation language. In fact, digital painting, whether it is "digital watercolor", "digital oil painting" or "digital engraving", can not be divided into painting categories. They lack the value embodiment of traditional painting's painting, spirituality and uniqueness, and are also difficult to escape from the digital virtual space. Therefore, different from the material characteristics of traditional watercolor, digital watercolor can not replace the artistic value of traditional watercolor, and simulation and reproduction are not the maximum embodiment of the advantages of digital watercolor. Any kind of art form has its own unique creation rules and application principles. Computer technology makes digital painting create close interaction between art and viewers, which makes the viewer experience the multidimensional art of vision, hearing and touch instantly. The simulation and reproduction function of digital technology brings rapidity and instantaneity to painting, and digital watercolor is widely used in various fields. Only by making full use of the strong technical and functional advantages and exerting its own practicability and technicality, can digital painting obtain a broader and free artistic space and realize the sustainable development in the future.

\section{Resume author}

Shan Li

Doctor of fine arts, Macau University of science and technology

Lecturer, School of fine arts, Baoji University of Arts and Sciences

Email: leestonefemale@126.com

Tel: 13689177682 / 13689177681

Address: Room 201, unit 1, building 11, Jufeng intercity community (phase II), Gaoxin 5th Road, Baoji, Shaanxi Province

Postcode: 721013

\section{References}

1. 3. Peng Shengfang, "digital painting" speculation, art research, March 2007.

2. Zhang Gengyun, digital painting creation, Southwest Normal University Press, February 2002 edition, 1 page.

4. Rong Wangqiao, influence the times and digital art, literature and art contention, December 2007.

5. Qin Hong, on the beauty of the overall composition of watercolor art, art observation, August 2014.

6. Aristotle, poetics, commercial press, July 1996.

7. Chen Xuguang, implication of art, China Renmin University Press, January 2000 edition, 154 pages. 